\title{
Coexpression of LAG-3 and PD-L1 in tumor infiltrating immune cells predicts worse outcome in clear cell renal cell carcinoma
}

\section{Chan Ho Lee}

Inje University College of Medicine

Soo Jin Jung ( $\nabla$ soojinmd@hanmail.net )

Inje University College of Medicine

\section{Won Ik Seo}

Inje University College of Medicine

Jae II Chung

Inje University College of Medicine

Dae Sim Lee

Inje University College of Medicine

Dae Hoon Jeong

Inje University College of Medicine

Youkyoung Jeon

Inje University College of Medicine

Inhak Choi

Inje University College of Medicine

\section{Research Article}

Keywords: LAG-3, renal cell carcinoma, immuno-oncology, immune checkpoints

Posted Date: March 7th, 2022

DOI: https://doi.org/10.21203/rs.3.rs-1413598/v1

License: (9) (i) This work is licensed under a Creative Commons Attribution 4.0 International License. Read Full License 


\section{Abstract}

Lymphocyte-activation gene 3 (LAG-3) protein is a potential immune checkpoint target for cancer treatment. Thus, we investigated LAG-3 expression and its prognostic value in clear cell renal cell carcinoma (ccRCC) and correlated LAG-3 expression with programmed cell death ligand 1 (PD-L1) using immunohistochemistry on tissue microarrays incorporating $134 \mathrm{ccRCC}$ primary excision specimens. The study patients were analyzed as two groups: the whole cohort and those with metastatic renal cell carcinoma (mRCC). LAG-3 expression was significantly correlated with PD-L1 expression in the whole cohort and in the mRCC group (all, $p<0.05$ ). Both LAG-3囚 RCC and PD-L1ه RCC in the whole cohort presented with a higher TNM stage and higher Fuhrman nuclear grade (all, $p<0.05$ ). According to the International Metastatic Renal Cell Carcinoma Database Consortium risk classification, there were more intermediate- and poor-risk patients in both LAG-3区 mRCC and PD-L $1 \rrbracket \mathrm{mRCC}$ than LAG-3囚 $\mathrm{mRCC}$ and PD-

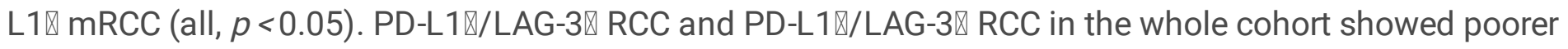
cancer-specific survival (CSS) than PD-L1区/LAG-3\RCC (all, $p=0.01$ ). Similarly, PD-L1区/LAG-3\ mRCC and

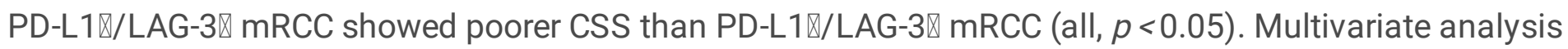
showed that PD-L1区/LAG-3区 mRCC (hazard ratio: 3.19; $p=0.033$ ) was a predictor of poor CSS. Our findings provided a scientific rationale for LAG-3 blockade in combination with programmed cell death 1/PD-L1 blockade as a potential therapeutic approach for RCC.

\section{Introduction}

Renal cell carcinoma (RCC) comprises approximately $90 \%$ of kidney cancer cases, of which $70 \%$ are clear cell RCC (ccRCC) [1]. Although the surgical resection of early-stage RCC has a good prognosis, the 5-year survival rates for relapsed or metastatic RCC (mRCC) have traditionally been quite low $(0 \%-20 \%)[2,3]$. In systemic treatment for $\mathrm{mRCC}$, systemic cytokine therapy, followed by targeted therapies, including tyrosine kinase inhibitors (TKIs) and inhibitors of mammalian target of rapamycin (mTOR), have been reported to prolong survival. However, approximately $20 \%-25 \%$ of patients derive no benefit from first-line targeted therapy or become treatment-resistant $[4,5]$. Fortunately, the introduction of immune checkpoint inhibitors (ICls) has revolutionized the treatment paradigm for mRCC. ICls targeting cytotoxic T-lymphocyteassociated protein 4, programmed cell death 1 (PD-1) receptor, or PD-1 ligand (PD-L1) have shown clinical efficacy in mRCC treatment [6,7]. Despite improved survival and treatment efficacy using ICls, the treatment efficacy of the checkpoint blockade in mRCC remains limited to a specific subpopulation of patients [8]. Thus, efforts are being made to find alternative pathways and auxiliary targets to overcome the limited efficacy of $\mathrm{ICl}$ treatment and treatment resistance.

Lymphocyte-activation gene 3 (LAG-3), also known as CD233, is an example of a new immune checkpoint target. This inhibitory receptor is mainly found on activated immune cells (ICs) and is involved in negative regulatory effects on T-cells and their biological functions related to immune and inflammatory responses $[9,10]$. Based on the coexpression of LAG-3 with other inhibitory receptors, recent preclinical and clinical evidence has revealed PD-1 pathway blockade in combination with LAG-3 inhibition as a potentially effective immunotherapy strategy [11]. However, the expression of LAG-3 and its coexpression with PD-L1 in primary RCC tissue has not been fully investigated. Additionally, the prognostic role of LAG-3 expression 
in RCC and the synergistic effect on prognosis upon coexpression with PD-L1 remains unclear. Therefore, we investigated the clinicopathological and prognostic significance of the coexpression of LAG-3 and PDL1 in primary ccRCC tumors.

\section{Materials And Methods}

\section{Patients}

Our study cohort comprised surgical specimens collected from 134 patients with ccRCC who had undergone radical or partial nephrectomy at the Inje University Busan Paik Hospital, South Korea, between January 2011 and January 2019. All pathological tissue specimens were provided by Inje Biobank. The study protocol conformed to the ethical guidelines of the 1975 Declaration of Helsinki, as reflected in a prior approval by the Institutional Review Board of Inje University Pusan Paik Hospital (approval no. 20-0121). Data on the histopathological features, such as histological subtype, tumor size, lymphovascular invasion, sarcomatoid features, Fuhrman nuclear grade, and distant metastases at surgery, were collected. The pathological stage was determined according to the 2010 version of the American Joint Committee on Cancer TNM staging system and the Heidelberg classification of renal tumors. The follow-up duration was calculated from the date of surgery to the date of the last follow-up or death. The study patients were analyzed as two groups, namely, the whole cohort and those with mRCC (determined according to the metastatic disease and systemic treatment status during follow-up). Clinical information regarding demographic characteristics, International Metastatic Renal Cell Carcinoma Database Consortium (IMDC) risk classification, and follow-up data were extracted from the patients' electronic medical records.

\section{Tissue microarrays (TMAs) and immunohistochemistry}

Six TMA blocks comprising a total of 402 cores were constructed by selecting invasive margins containing viable and representative tumor cells (TCs) and stroma with tumor-infiltrating ICs, including macrophages and lymphocytes, from formalin-fixed paraffin-embedded (FFPE) primary RCC tissue blocks of 134 patients. Three 2-mm diameter cores were selected from each case. From each TMA block, 4- $\mu$ m-thick sections were cut and stained with LAG-3 (1:200; clone D2G40, Cell Signaling Technology, MA, USA) and PD-L1 (1:100; clone SP263, Ventana Medical Systems, Inc., AZ, USA) primary antibodies. Normal human FFPE tonsil sections treated with and without these primary antibodies were used as positive and negative controls, respectively. LAG-3 staining was performed using a Dako REAL EnVision Detection System (K5007; Agilent Technologies, CA, USA) according to the manufacturer's protocol, while PD-L1 staining was performed using an OptiView DAB IHC Detection Kit (Ventana) on a BenchMark ULTRA automated platform (Ventana), according to the manufacturer's protocol.

\section{LAG-3 and PD-L1 scoring}

TMAs and individual slides were visually scored by an experienced pathologist blinded to clinical information. LAG-3 and PD-L1 scoring of ICs is a controversial matter in the current literature; in our study, we used the method of Burugu et al. and Motzer et al. [12, 13]. LAG-3 scores were reported as absolute counts, and any positive expression on ICs ( $\geq 1$ IC per TMA core) was used for dichotomization into positive 
and negative cases. IC expression of PD-L1 was assessed as the percentage of ICs with membranous or cytoplasmic expression; any cores with $\geq 1 \%$ of PD-L $1^{+}$ICs were considered positive. All IC types, including macrophages and lymphocytes, were counted together to calculate the LAG-3 and PD-L1 scores. PD-L1 expression in TCs was assessed as the percentage of carcinoma cells with membranous expression at any intensity. Any expression of $\geq 1 \%$ in a TMA core that included at least 100 evaluable TCs was considered positive [7]. For the final statistical analysis, PD-L1 ${ }^{+}$cells were defined as any positive PD-L1 staining on ICs or TCs. The three tumor TMA cores for each case were independently scored, and if any of the three cores were positive, that case was considered positive in the statistical analysis.

\section{Statistical analysis}

Continuous variables were presented as means (standard deviation) or medians (interquartile ranges, IQRs). Categorical variables were presented as frequencies with percentages. Differences in the distribution of variables among groups were evaluated using the chi-square test, Fisher exact test, and linear-by-linear association for categorical variables. The Student t-test was used for continuous variables. CSS according to the expression status of immune markers was estimated using the Kaplan-Meier method and compared using the log-rank test. Univariate and multivariate Cox proportional-hazard models adjusted by LAG-3 and PD-L1 expression status were utilized to identify any clinicopathological factors that might have affected CSS. The risk was expressed as the hazard ratio (HR), and the $95 \%$ confidence interval $(\mathrm{Cl})$ was determined using the reference groups. Statistical analysis was performed with SPSS v25.0 (IBM Corp., Armonk, NY, USA) and MedCalc v20.0 (MedCalc Software, Ostend, Belgium). In all tests, a two-sided p-value $<0.05$ was considered statistically significant.

\section{Results}

\section{Patient characteristics}

The study cohort comprised 134 patients who underwent surgical resection of primary ccRCC. The patients' demographic data and clinicopathological features are summarized in Table 1. The median age of the whole cohort at the time of surgery was 61 years (IQR, 34-82), and the 134 patients included 94 men (70.1\%). Among the 134 cases, 25 (18.7\%) presented with synchronous metastasis, and 26 (19.4\%) experienced disease recurrence during the follow-up period. Of the 51 patients with metastatic disease, 45 were treated with targeted therapy, including TKIs and mTOR inhibitors. According to the IMDC risk classification, 20 (44.4\%) of these patients were classed as favorable risk, $10(22.2 \%)$ as intermediate risk, and $15(33.3 \%)$ as poor risk. During a mean follow-up period of 89.6 months (95\% Cl: 80.0-99.3 months; median survival, not reached), 32 of the 134 (23.9\%) patients died after surgery for RCC. In the case of mRCC, 28 patients (62.2\%) died after diagnosis of metastatic disease, with a median follow-up of 18.0 months (95\% Cl: $11.0-43.0)$.

\section{LAG-3 and PD-L1 expression}

Immunohistochemistry detected the expression of LAG-3 protein in the nucleus and cytoplasm of ICs, but LAG-3 protein was not detected on TCs. In the whole cohort of 134 RCC patients, LAG-3 was positive in 68 
(50.7\%) cases. The expression of PD-L1 on ICs was positive in 45 (33.6\%) cases, whereas 34 (25.4\%) expressed PD-L1 on TCs. Taken together, PD-L1区 RCC was observed in 59 (44.0\%) RCC patients. LAG-3 was positive in 31 (68.9\%) mRCC patients. PD-L1 \ ICs and TCs were observed in 20 (44.4\%) and 17 (37.8\%) mRCC patients, of which 25 (55.6\%) were PD-L1》 mRCC. LAG-3 expression was significantly correlated with PD-L1 expression in the whole cohort and with mRCC. In summary, in the whole cohort, $64.7 \%$ of the cases

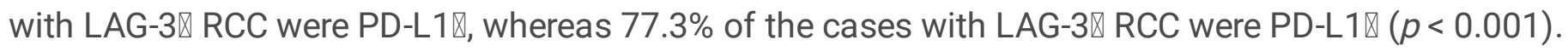
Similarly, in mRCC, $67.7 \%$ of the cases with LAG-3\ mRCC were PD-L1区, whereas $71.4 \%$ of the cases with LAG-3凶 mRCC were PD-L1区 $(p=0.016)$ (Table 2) (Fig.1).

\section{Clinicopathological significance of LAG-3 and PD-L1 expression}

Both LAG-3囚 RCC and PD-L1区 RCC presented with higher TNM stage and higher Fuhrman nuclear grade (all, $p<0.05$ ) (Fig.2). PD-L1区 RCC presented with more tumor necrosis ( $p=0.028$ ) (Table 3). Both LAG-3\ mRCC and PD-L1ه mRCC presented with more IMDC intermediate and poor risk patients than LAG-3区 mRCC and PD-L1D mRCC (all, $p<0.05$ ). Only PD-L1囚 mRCC showed higher TNM stage, higher Fuhrman nuclear grade, more sarcomatoid features, and more tumor necrosis (all, $p<0.05$ ).

\section{Relationship of cancer specific survival with LAG-3 and PD-L1 expressions}

Patients with LAG-3\ RCC had significantly poorer CSS than patients with LAG-3\ RCC. The mean CSS was 60.4 months (95\% Cl: 50.9-69.9) in LAG-3囚 RCC and 101.4 months (95\% Cl: 89.1-113.6) in LAG-3凶 RCC (HR: 3.11; 95\% Cl: 1.53-6.30; $p=0.0016$ ) (Fig. 3a). Similarly, patients with PD-L1囚 RCC showed significantly poorer CSS than patients with PD-L1区 RCC (mean, 63.7 months [95\% Cl: 53.6-73.7] vs. mean, 96.3 months [95\% Cl: 84.8-107.8]; HR: 2.31; 95\% Cl: 1.11-4.77; $p=0.0236$ ) (Fig. 3b). The differences between the four subgroups classified according to LAG-3 and PD-L1 expression were not statistically significant, but PD-

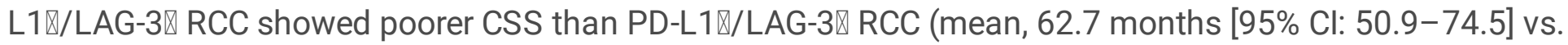
mean, 105.4 months [95\% Cl: 92.5-118.4]; HR: 4.62; 95\% Cl: 1.80-11.87; $p=0.0014)$. Additionally, PD-

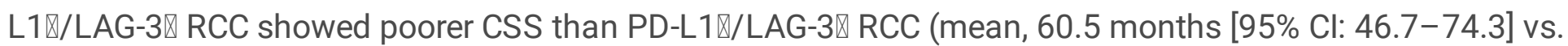
mean, 105.4 months [95\% Cl: 92.5-118.4]; HR: 6.26; 95\% Cl: 1.93-20.26; $p=0.0022)$ (Fig. 3c).

Similar results were also observed in mRCC. The median CSS was 13.0 months (95\% Cl: 6.0-36.0) in LAG$3 \rrbracket \mathrm{mRCC}$ and 43.0 months (95\% Cl: 9.0-43.0) in LAG-3凶 mRCC (HR: 2.30; 95\% Cl: 1.05- 5.06; $p=0.0369)$ (Fig. 3d). The median CSS was 22.5 months (95\% Cl: 13.0-31.9) in PD-L1囚 mRCC and 11.0 months (95\%

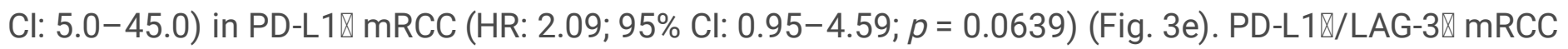
showed poorer CSS than PD-L1区/LAG-3囚 mRCC (median, 11.0 months [95\% Cl: 5.00-45.0] vs. not reached; HR: 2.91; 95\% Cl: 1.05-8.04; $p=0.0389)$. PD-L1区/LAG-3® mRCC also showed poorer CSS than PDL1ه/LAG-3》 mRCC (median, 30.0 months [95\% Cl: 4.00-37.0] vs. not reached; HR: 4.74; 95\% Cl: 1.35-16.61; $p=0.0149)$ (Fig. 3f).

In the univariate analysis, LAG-3区, PD-L1区, and PD-L1区/LAG-3》 (all, $p<0.05$ ) were significant unfavorable prognostic factors in the whole cohort and in the mRCC group (Supplementary Table 1). Multivariate analysis revealed only PD-L1区/LAG-3\ mRCC (HR: 3.19; 95\% Cl: 0.77-13.67; $p=0.033$ ) as a predictor of poor CSS (Supplementary Table 2). 


\section{Discussion}

Recently, several immune checkpoints on tumor-infiltrating ICs, which are key regulators of the immune escape of cancer cells, were studied and clinically applied to the treatment of various solid tumors. In primary CCRCC, PD-1 or PD-L1 inhibitors, which are hallmark immunological treatments, have offered a survival benefit in this decade [14]. However, even after such immunotherapy, a significant number of patients still show refractory disease or acquire resistance [8]. Therefore, demands for new therapeutic targets have emerged, of which is LAG-3 is attracting attention.

LAG-3 is mainly expressed in activated T-cells and natural killer cells and was identified as a marker of CD4 $\triangle$ and CD8 T-cell activation [15]. Enhanced LAG-3 expression on T-cells in combination with PD-1 has been reported under pathological conditions, such as inflammation or the tumor microenvironment [9]. In this study, we confirmed that LAG-3 expression in RCC tissue was expressed only in ICs, not TCs. Our study confirmed that LAG-3 was only expressed on ICs, not TCs, of RCC tissue. Similarly, tumor-infiltrating lymphocytes isolated from patients with hepatocellular carcinoma [16], ovarian cancer [17], breast cancer [12], and melanoma [18] showed significant upregulation of LAG-3. Additionally, these studies noted the function of LAG-3 as an immune checkpoint molecule, demonstrating its potential role as a target for cancer immunotherapy in various solid tumors. However, only a limited number of studies examining the role of LAG-3 in kidney cancer using tissues derived from kidney cancer patients have been reported. Giraldo et al. reported the prognostic role of PD-L2 and LAG-3 in the immunomodulation of ccRCC [19]. Zelba et al. used flow cytometry analysis to reveal that PD-1 and LAG-3 were the most frequently upregulated inhibitory receptors within RCC tumor-infiltrating lymphocytes [20]. Most recently, there was a report of poor survival in ccRCC with LAG-3 expression and LAG-3 DNA methylation [21].

The exact mechanism underlying LAG-3 function in cancer treatment, including RCC, has been poorly studied. Fortunately, based on the pan-caner analysis of The Cancer Genome Atlas dataset, Panda et al. reported that the expression of cytotoxic T-cell marker CD8A was strongly correlated with LAG-3 expression in various cancers, including RCC [22]. This suggests that tumors with strong CD8 + T-cell infiltration tend to have a high level of LAG-3 expression. Because CD8 + T-cell infiltrates in cancer are correlated with local immune activation and the response to immune checkpoint therapy [23], LAG-3 blockade could be a reasonable strategy for cancer immunotherapy.

In this tissue-based cohort study on surgically resected ccRCC, we found that LAG-3 expression is a prognostic indicator for poor CSS in CCRCC. Unlike previous studies reporting a simple survival analysis according to the LAG-3 expression status $[19,21]$, our study analyzed the predictive and prognostic implication of LAG-3 in comparison with various clinicopathological features associated with aggressive tumor behavior, including PT stage, grade, lymphovascular invasion, tumor necrosis, and sarcomatoid features, in tissue samples from patients with RCC. In fact, LAG-3 immunopositivity on ICs in tumor tissues was associated with an advanced pT stage and higher Fuhrman nuclear grade. Systemic treatment using ICls is the main therapeutic approach for mRCC rather than for localized RCC, which can be cured by surgical treatment. Thus, it is more relevant to evaluate the prognostic value of LAG-3 in mRCC. Accordingly, 
the subgroup analysis consisted of mRCC patients who were treated with targeted therapy, and we demonstrated poor survival in patients with RCC who had LAG-3+ primary tumors.

The major strength of our study was the examination of the correlation between LAG-3 and PD-L1 expression and the synergistic effect on RCC prognosis when both immune checkpoint molecules were expressed simultaneously. The expression rate of PD-L1 on TCs was similar to that of previous studies, but the expression rate of PD-L1 on ICs was relatively lower than previous reports [13,24]. Differences in patient cohorts, the types of antibodies used in immunohistochemistry experiments, and the selection of cutoffs can contribute to this discrepancy. The expression of PD-L1 on TCs or ICs was positively correlated with LAG-3 expression in our study. Our results demonstrated that PD-L1区/LAG-3区 RCC patients had a poorer CSS than PD-L1区/LAG-3囚 RCC patients. Furthermore, in the multivariate analysis using a subgroup consisting of mRCC patients only, PD-L1 and LAG-3 coexpression was found to be a significant predictor of poor CSS. Because LAG-3 and PD-1 synergistically regulate T-cell function to promote tumoral immune

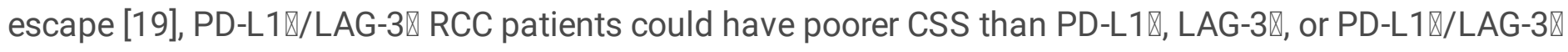
RCC patients. A similar result was reported in a study comparing the relationship between LAG-3 and PD-L1 in non-small cell lung cancer [25].

Recent clinical trials have shown that high levels of PD-L1 expression are associated with a worse prognosis, but when treated with PD-1/PD-L1 inhibitors, patients with higher levels of PD-L1 expression tend to respond better to therapy [26]. However, since a significant number of patients do not respond to PD1/PD-L1-targeting therapy regardless of their PD-1/PD-L1 expression status, alternative pathways need to be identified to overcome refractory disease or resistance to anti-PD-1/PD-L1 treatment. After blocking PD1/PD-L1, TCs can still counteract the activity of immune checkpoints and activate additional inhibitory pathways by expressing other immune checkpoints and their ligand within the tumor immune microenvironment [27]. Indeed, LAG-3 cell-surface expression was upregulated in vitro upon PD-1 blockade using patient-derived RCC tissue [20]. Fortunately, recent clinical research on melanoma demonstrated that LAG-3 might have a synergistic effect with PD-1/PD-L1, and the combination of anti-LAG-3 and anti-PD-1 treatment revealed exciting effects in tumors that were resistant to previous PD-L1 blockers [28]. In line with these findings, our results that PD-L1区/LAG-3囚 or PD-L1区/LAG-3囚 RCC and mRCC had significantly poorer CSS than PD-L1区/LAG-3囚 RCC and mRCC suggest that anti-LAG-3 monotherapy or a combination of antiLAG-3 and anti-PD-1/PD-L1 treatment could be beneficial for LAG-3\ RCC patients who are refractory or resistant to anti-PD-1/PD-L1 treatment.

Our study had several limitations. First, although we identified the association of LAG-3 expression in ccRCC with known risk factors for survival, some clinicopathological factors were not statistically significant because of our study's retrospective design and relatively small number sample size. Therefore, additional prospective studies with a large patient cohort are necessary to confirm our results. Second, the TMA of the primary tumor tissue cannot completely reflect the immune markers analyzed in the tumor microenvironment. Additionally, although we showed LAG-3 and PD-L1 expression on ICs, we could not evaluate the IC type-specific expression of either checkpoint molecule. Third, despite recent advances in ICls in the treatment of $\mathrm{mRCC}$, our study only includes a survival analysis of $\mathrm{mRCC}$ patients who were treated with targeted therapy. However, because previous studies show the poor prognostic role of PD-L1 
expression in $\mathrm{mRCC}$ patients who were treated with targeted therapy, our results of the analysis of the prognostic role of LAG-3 in cCRCC and mRCC could be clinically relevant [29,30]. In the near future, the results of ongoing clinical trials using an anti-LAG-3 mAb, such as relatlimab, will be used to determine the prognostic role of LAG-3 for various solid tumors, including RCC [11].

In conclusion, our study demonstrated that LAG-3 and PD-L1 expression in CCRCC is positively correlated with adverse clinicopathological features. Additionally, the coexpression of LAG-3 and PD-L1 predicts poor clinical outcomes in CCRCC. These findings provide a scientific rationale for LAG-3 blockade in combination with PD-1/PD-L1 blockade as a potential therapeutic approach for ccRCC. Data from ongoing clinical trials are required to validate these hypotheses.

\section{Abbreviations}

ccRCC Clear cell renal cell carcinoma

CSS Cancer specific survival

ICI Immune check point inhibitor

ICs Immune cells

IMDC International Mestastatic Renal cell carcinoma databe consortium

LAG-3 Lymphocyte-activation gene 3

mRCC Metastatic renal cell carcinoma

mTOR Mammalian target of rapamycin

PD-L1 Programmed death ligand-1

TCs Tumor cells

TKI Tyrosin kinase inhibitor

TMA Tissue microarray

\section{Declarations}

\section{Acknowledgements}

The biospecimens used in this study were provided by the Inje Biobank of Inje University Busan Paik Hospital, a member of Korea Biobank Network. And this work was supported by the National Research Foundation of Korea (NRF) grant funded by the Korea government (MSIT; No. 2020R1F1A1071003). 
Funding: This work was supported by the National Research Foundation of Korea (NRF) grant funded by the Korea government (MSIT; No. 2020R1F1A1071003).

Conflicts of interest: The authors have no relevant financial or non-financial interests to disclose.

Author's contributions: All authors contributed to the study conception and design. Material preparation, data collection and analysis were performed by Chan Ho Lee, Soo Jin Jung, Won Ik Seo, Youkyoung Jeon, Dae Sim Lee. Acquisition and interpretation of data were performed by Chan Ho Lee, Soo Jin Jung. The first draft of the manuscript was written by Chan Ho Lee and re-writing and editing the manuscript was performed by Soo Jin Jung. All authors commented on previous versions of the manuscript and read and approved the final manuscript.

Data availability: The datasets generated and analyzed during the current study are available from the corresponding author on reasonable request.

Ethics approval: This study was approved by the Busan Paik Hospital Institutional Review Board (IRB No. 20-0121) and was in compliance with ethical guidelines according to the Declaration of Helsinki.

Consent to participate: Informed consent was waived by the Busan Paik Hospital Institutional Review Board on the grounds of being a retrospective study using tumor tissue already archived by the Inje Biobank

Consent for publish: This study did not include any form of personally identifiable data.

\section{References}

1. Znaor A, Lortet-Tieulent J, Laversanne M, Jemal A, Bray F (2015) International variations and trends in renal cell carcinoma incidence and mortality. Eur Urol. 67(3):519-530. https://doi.org/10.1016/j.eururo.2014.10.002

2. Mekhail TM, Abou-Jawde RM, Boumerhi G, Malhi S, Wood L, Elson P, Bukowski R (2005) Validation and extension of the Memorial Sloan-Kettering prognostic factors model for survival in patients with previously untreated metastatic renal cell carcinoma. J Clin Oncol. 23(4):832-841. https://doi.org/10.1200/jco.2005.05.179

3. Heng DY, Xie W, Regan MM et al. (2009) Prognostic factors for overall survival in patients with metastatic renal cell carcinoma treated with vascular endothelial growth factor-targeted agents: results from a large, multicenter study. J Clin Oncol. 27(34):5794-5799. https://doi.org/10.1200/jco.2008.21.4809

4. Motzer RJ, Hutson TE, Tomczak P et al. (2009) Overall survival and updated results for sunitinib compared with interferon alfa in patients with metastatic renal cell carcinoma. J Clin Oncol. 27(22):3584-3590. https://doi.org/10.1200/jco.2008.20.1293

5. Sternberg CN, Davis ID, Mardiak J et al. (2010) Pazopanib in locally advanced or metastatic renal cell carcinoma: results of a randomized phase III trial. J Clin Oncol. 28(6):1061-1068. https://doi.org/10.1200/jco.2009.23.9764 
6. Motzer RJ, Escudier B, McDermott DF et al. (2015) Nivolumab versus Everolimus in Advanced RenalCell Carcinoma. N Engl J Med. 373(19):1803-1813. https://doi.org/10.1056/NEJMoa1510665

7. Motzer RJ, Tannir NM, McDermott DF et al. (2018) Nivolumab plus Ipilimumab versus Sunitinib in Advanced Renal-Cell Carcinoma. N Engl J Med. 378(14):1277-1290. https://doi.org/10.1056/NEJMoa1712126

8. Rini BI, Battle D, Figlin RA et al. (2019) The society for immunotherapy of cancer consensus statement on immunotherapy for the treatment of advanced renal cell carcinoma (RCC). J Immunother Cancer. 7(1):354. https://doi.org/10.1186/s40425-019-0813-8

9. Zarour HM (2016) Reversing T-cell Dysfunction and Exhaustion in Cancer. Clin Cancer Res. 22(8):18561864. https://doi.org/10.1158/1078-0432.ccr-15-1849

10. Andrews LP, Marciscano AE, Drake CG, Vignali DA (2017) LAG3 (CD223) as a cancer immunotherapy target. Immunol Rev. 276(1):80-96. https://doi.org/10.1111/imr.12519

11. Puhr HC, Ilhan-Mutlu A (2019) New emerging targets in cancer immunotherapy: the role of LAG3. ESMO Open. 4(2):e000482. https://doi.org/https://doi.org/10.1136/esmoopen-2018-000482

12. Burugu S, Gao D, Leung S, Chia SK, Nielsen TO (2017) LAG-3+ tumor infiltrating lymphocytes in breast cancer: clinical correlates and association with PD-1/PD-L1+ tumors. Ann Oncol. 28(12):2977-2984. https://doi.org/10.1093/annonc/mdx557

13. Motzer RJ, Penkov K, Haanen J et al. (2019) Avelumab plus Axitinib versus Sunitinib for Advanced Renal-Cell Carcinoma. N Engl J Med. 380(12):1103-1115. https://doi.org/10.1056/NEJMoa1816047

14. Motzer RJ, Jonasch E, Boyle S et al. (2020) NCCN Guidelines Insights: Kidney Cancer, Version 1.2021. J Natl Compr Canc Netw. 18(9):1160-1170. https://doi.org/10.6004/jnccn.2020.0043

15. Workman CJ, Rice DS, Dugger KJ, Kurschner C, Vignali DA (2002) Phenotypic analysis of the murine CD4-related glycoprotein, CD223 (LAG-3). Eur J Immunol. 32(8):2255-2263. https://doi.org/10.1002/1521-4141(200208)32:8<2255::aid-immu2255>3.0.co;2-a

16. Guo M, Yuan F, Qi F et al. (2020) Expression and clinical significance of LAG-3, FGL1, PD-L1 and CD8(+)T cells in hepatocellular carcinoma using multiplex quantitative analysis. J Transl Med. 18(1):306. https://doi.org/10.1186/s12967-020-02469-8

17. Matsuzaki J, Gnjatic S, Mhawech-Fauceglia P et al. (2010) Tumor-infiltrating NY-ESO-1-specific CD8+ T cells are negatively regulated by LAG-3 and PD-1 in human ovarian cancer. Proc Natl Acad Sci U S A. 107(17):7875-7880. https://doi.org/10.1073/pnas.1003345107

18. Baitsch L, Baumgaertner P, Devêvre E et al. (2011) Exhaustion of tumor-specific CD8\ T cells in metastases from melanoma patients. J Clin Invest. 121(6):2350-2360.

https://doi.org/10.1172/jci46102

19. Giraldo NA, Becht E, Pagès F et al. (2015) Orchestration and Prognostic Significance of Immune Checkpoints in the Microenvironment of Primary and Metastatic Renal Cell Cancer. Clin Cancer Res. 21(13):3031-3040. https://doi.org/10.1158/1078-0432.ccr-14-2926

20. Zelba H, Bedke J, Hennenlotter J et al. (2019) PD-1 and LAG-3 Dominate Checkpoint Receptor-Mediated T-cell Inhibition in Renal Cell Carcinoma. Cancer Immunol Res. 7(11):1891-1899. 
https://doi.org/10.1158/2326-6066.cir-19-0146

21. Klümper N, Ralser DJ, Bawden EG et al. (2020) LAG3 (LAG-3, CD223) DNA methylation correlates with LAG3 expression by tumor and immune cells, immune cell infiltration, and overall survival in clear cell renal cell carcinoma. J Immunother Cancer. 8(1). https://doi.org/10.1136/jitc-2020-000552

22. Panda A, Rosenfeld JA, Singer EA, Bhanot G, Ganesan S (2020) Genomic and immunologic correlates of LAG-3 expression in cancer. Oncoimmunology. 9(1):1756116-1756116. https://doi.org/10.1080/2162402X.2020.1756116

23. Tumeh PC, Harview CL, Yearley JH et al. (2014) PD-1 blockade induces responses by inhibiting adaptive immune resistance. Nature. 515(7528):568-571. https://doi.org/10.1038/nature13954

24. Thompson RH, Kuntz SM, Leibovich BC et al. (2006) Tumor B7-H1 is associated with poor prognosis in renal cell carcinoma patients with long-term follow-up. Cancer Res. 66(7):3381-3385. https://doi.org/10.1158/0008-5472.can-05-4303

25. He Y, Yu H, Rozeboom L et al. (2017) LAG-3 Protein Expression in Non-Small Cell Lung Cancer and Its Relationship with PD-1/PD-L1 and Tumor-Infiltrating Lymphocytes. J Thorac Oncol. 12(5):814-823. https://doi.org/10.1016/j.jtho.2017.01.019

26. Sati N, Boyne DJ, Cheung WY, Cash SB, Arora P (2021) Factors Modifying the Associations of Single or Combination Programmed Cell Death 1 and Programmed Cell Death Ligand 1 Inhibitor Therapies With Survival Outcomes in Patients With Metastatic Clear Cell Renal Cell Carcinoma: A Systematic Review and Meta-analysis. JAMA Netw Open. 4(1):e2034201. https://doi.org/10.1001/jamanetworkopen.2020.34201

27. Toor SM, Sasidharan Nair V, Decock J, Elkord E (2020) Immune checkpoints in the tumor microenvironment. Semin Cancer Biol. 65:1-12. https://doi.org/10.1016/j.semcancer.2019.06.021

28. Ascierto PA, Bono P, Bhatia S et al. (2017) Efficacy of BMS-986016, a monoclonal antibody that targets lymphocyte activation gene-3 (LAG-3), in combination with nivolumab in pts with melanoma who progressed during prior anti\&\#x2013;PD-1/PD-L1 therapy (mel prior IO) in all-comer and biomarkerenriched populations. Annals of Oncology. 28:v611-v612.

https://doi.org/10.1093/annonc/mdx440.011

29. Choueiri TK, Figueroa DJ, Fay AP et al. (2015) Correlation of PD-L1 tumor expression and treatment outcomes in patients with renal cell carcinoma receiving sunitinib or pazopanib: results from COMPARZ, a randomized controlled trial. Clin Cancer Res. 21(5):1071-1077. https://doi.org/10.1158/1078-0432.ccr-14-1993

30. Shin SJ, Jeon YK, Cho YM, Lee JL, Chung DH, Park JY, Go H (2015) The Association Between PD-L1 Expression and the Clinical Outcomes to Vascular Endothelial Growth Factor-Targeted Therapy in Patients With Metastatic Clear Cell Renal Cell Carcinoma. Oncologist. 20(11):1253-1260. https://doi.org/10.1634/theoncologist.2015-0151

\section{Tables}

Table 1 Clinicopathologic characteristics for renal cell carcinoma patients 


\begin{tabular}{lll} 
Characteristic & Whole cohort & Metastatic RCC \\
\cline { 2 - 3 } & $\mathrm{N}=134$ & $\mathrm{~N}=45$ \\
\hline $\begin{array}{l}\text { Age at surgery, } \\
\text { years (median, IQR) }\end{array}$ & $61(34-82)$ & $63(40-81)$ \\
& &
\end{tabular}

\begin{tabular}{lll}
\hline Gender, $\mathrm{n}(\%)$ & & \\
\hline Male & $94(70.1)$ & $32(71.1)$ \\
\hline Female & $40(29.9)$ & $13(28.9)$ \\
\hline & & \\
\hline $\begin{array}{l}\text { Tumor size, } \\
\mathrm{cm}(\text { median, IQR) }\end{array}$ & $5.5(1.2-13)$ & $6.5(1.2-9.2)$ \\
& & \\
\hline
\end{tabular}

T stage, n (\%)

\begin{tabular}{lll}
\hline pT1 & $78(58.2)$ & $12(26.7)$ \\
\hline pT2 & $19(14.2)$ & $9(20.0)$ \\
\hline pT3 & $33(24.6)$ & $21(46.7)$ \\
\hline pT4 & $4(3.0)$ & $3(6.7)$ \\
\hline
\end{tabular}

\begin{tabular}{lll}
\hline $\mathrm{N}$ stage, $\mathrm{n}(\%)$ & & \\
\hline $\mathrm{cN} 0$ & $122(91.0)$ & $35(77.8)$ \\
\hline $\mathrm{cN} 1$ & $12(9.0)$ & $10(22.2)$ \\
\hline
\end{tabular}

\begin{tabular}{lll}
\hline M stage, $n(\%)$ & \\
\hline CM0 & $109(81.3)$ & $22(48.9)$ \\
\hline CM1 & $25(18.7)$ & $23(51.2)$ \\
\hline
\end{tabular}

Stage, n (\%)

\begin{tabular}{lll} 
Stage I & $72(53.7)$ & $6(13.3)$ \\
\hline Stage II & $15(11.2)$ & $5(11.1)$ \\
\hline Stage III & $22(16.4)$ & $11(24.4)$ \\
\hline
\end{tabular}


Fuhrman nuclear grade, $\mathrm{n}(\%)$

\begin{tabular}{lll} 
G1 - G2 & $65(48.5)$ & $10(22.2)$ \\
\hline G3 & $51(38.1)$ & $20(44.4)$ \\
\hline G4 & $18(13.4)$ & $15(33.3)$
\end{tabular}

Lymphovascular invasion, $\mathrm{n}(\%)$

\begin{tabular}{lll}
\hline No & $118(88.1)$ & $34(75.6)$ \\
\hline Yes & $16(11.9)$ & $11(24.4)$
\end{tabular}

Sarcomatoid features, $\mathrm{n}(\%)$

$\begin{array}{lll}\text { No } & 126(94.0) & 39(86.7) \\ \text { Yes } & 8(6.0) & 6(13.3)\end{array}$

Tumor necrosis, $\mathrm{n}(\%)$

\begin{tabular}{lll} 
No & $103(76.9)$ & $24(53.3)$ \\
\hline Yes & $31(23.1)$ & $21(46.7)$
\end{tabular}

IMDC risk classification

\begin{tabular}{lcc} 
Favorable & - & $20(44.4)$ \\
\hline Intermediate & - & $10(22.2)$ \\
\hline Poor & - & $15(33.3)$
\end{tabular}

Table 2 Expression of LAG-3 and PD-L1 in clear cell renal cell carcinoma 


\begin{tabular}{|c|c|c|c|c|c|c|c|c|}
\hline \multirow[t]{2}{*}{ Characteristics } & \multicolumn{4}{|c|}{ LAG-3 in Whole cohort } & \multicolumn{4}{|c|}{ LAG-3 in Metastatic RCC } \\
\hline & Total & Positive & Negative & $p$ value & Total & Positive & Negative & $\begin{array}{l}p \\
\text { value }\end{array}$ \\
\hline \multicolumn{9}{|c|}{ PD-L1 in ICs, n (\%) } \\
\hline Positive & $\begin{array}{l}45 \\
(33.6)\end{array}$ & $\begin{array}{l}34 \\
(50.0)\end{array}$ & $11(16.7)$ & $<0.001$ & $\begin{array}{l}20 \\
(44.4)\end{array}$ & $\begin{array}{l}16 \\
(51.6)\end{array}$ & $4(28.6)$ & 0.154 \\
\hline Negative & $\begin{array}{l}89 \\
(66.4)\end{array}$ & $\begin{array}{l}34 \\
(50.0)\end{array}$ & 55 (83.3) & & $\begin{array}{l}25 \\
(55.6)\end{array}$ & $\begin{array}{l}15 \\
(48.4)\end{array}$ & $\begin{array}{l}10 \\
(71.4)\end{array}$ & \\
\hline \multicolumn{9}{|c|}{ PD-L1 in TCs, $\mathrm{n}(\%)$} \\
\hline Positive & $\begin{array}{l}34 \\
(25.4)\end{array}$ & $\begin{array}{l}25 \\
(36.8)\end{array}$ & $9(13.6)$ & 0.002 & $\begin{array}{l}17 \\
(37.8)\end{array}$ & $\begin{array}{l}15 \\
(48.4)\end{array}$ & $2(14.3)$ & 0.030 \\
\hline Negative & $\begin{array}{l}100 \\
(74.6)\end{array}$ & $\begin{array}{l}43 \\
(63.2)\end{array}$ & $57(86.4)$ & & $\begin{array}{l}28 \\
(62.2)\end{array}$ & $\begin{array}{l}16 \\
(51.6)\end{array}$ & $\begin{array}{l}12 \\
(85.7)\end{array}$ & \\
\hline \multicolumn{9}{|c|}{ PD-L1 in overall, $n(\%)$} \\
\hline Positive & $\begin{array}{l}59 \\
(44.0)\end{array}$ & $\begin{array}{l}44 \\
(64.7)\end{array}$ & 15 (22.7) & $<0.001$ & $\begin{array}{l}25 \\
(55.6)\end{array}$ & $\begin{array}{l}21 \\
(67.7)\end{array}$ & $4(28.6)$ & 0.016 \\
\hline Negative & $\begin{array}{l}75 \\
(56.0)\end{array}$ & $\begin{array}{l}24 \\
(35.3)\end{array}$ & $51(77.3)$ & & $\begin{array}{l}20 \\
(44.4)\end{array}$ & $\begin{array}{l}10 \\
(32.3)\end{array}$ & $\begin{array}{l}10 \\
(71.4)\end{array}$ & \\
\hline
\end{tabular}

Table 3 Relationship of LAG-3 expression and clinicopathologic features in clear cell renal cell carcinoma 
Whole cohort

Characteristic

Metastatic RCC

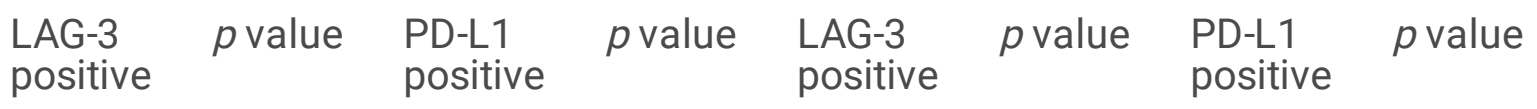
$\mathrm{n}=68$
$\mathrm{n}=59$
$\mathrm{n}=31$
$\mathrm{n}=25$

Pathologic T

stage, $\mathrm{n}(\%)$

\begin{tabular}{|c|c|c|c|c|c|c|c|c|}
\hline pT1 & $\begin{array}{l}31 \\
(45.6)\end{array}$ & 0.006 & $\begin{array}{l}28 \\
(47.4)\end{array}$ & 0.008 & $7(22.6)$ & 0.210 & $3(12.0)$ & 0.002 \\
\hline pT2 & $\begin{array}{l}12 \\
(17.7)\end{array}$ & & $8(13.6)$ & & $5(16.1)$ & & $4(16.0)$ & \\
\hline pT3 & $\begin{array}{l}23 \\
(33.8)\end{array}$ & & $\begin{array}{l}20 \\
(33.9)\end{array}$ & & $\begin{array}{l}17 \\
(54.8)\end{array}$ & & $\begin{array}{l}15 \\
(60.0)\end{array}$ & \\
\hline pT4 & $2(2.9)$ & & $3(5.1)$ & & $2(6.5)$ & & $3(12.0)$ & \\
\hline
\end{tabular}

Clinical N stage,

$\mathrm{n}(\%)$

\begin{tabular}{lllllllll} 
cN0 & 60 & 0.249 & $\begin{array}{l}50 \\
(84.7)\end{array}$ & 0.024 & 23 & 0.394 & 16 & 0.014 \\
& $(88.2)$ & & $(74.2)$ & & $(64.0)$ & \\
\hline cN1 & $8(11.8)$ & & $9(15.3)$ & & $8(25.8)$ & & $9(36.0)$ &
\end{tabular}

Clinical M stage,

$\mathrm{n}(\%)$

\begin{tabular}{|c|c|c|c|c|c|c|c|}
\hline cMO & $\begin{array}{l}50 \\
(73.5)\end{array}$ & 0.018 & $\begin{array}{l}41 \\
(69.5)\end{array}$ & 0.002 & $\begin{array}{l}13 \\
(41.9)\end{array}$ & 0.169 & $7(28.0)$ \\
\hline CM1 & $\begin{array}{l}18 \\
(26.5)\end{array}$ & & $\begin{array}{l}18 \\
(30.5)\end{array}$ & & $\begin{array}{l}18 \\
(58.1)\end{array}$ & & $\begin{array}{l}18 \\
(72.0)\end{array}$ \\
\hline
\end{tabular}

Stage, $\mathrm{n}(\%)$

Stage I

$27 \quad 0.001 \quad 26$

(39.7)

(44.1)

Stage II

$9(13.2)$

$4(6.8)$

$0.002 \quad 3(9.7) \quad 0.076$

$1(4.0) \quad<0.001$

Stage III

14

(20.6)

11

(18.6)

Stage IV

18
$(26.5)$

18

(30.5)

2 (6.5)

$0(0.0)$

$8(25.8)$

$6(24.0)$

Fuhrman

nuclear grade, $\mathrm{n}$

(\%)

\begin{tabular}{|c|c|c|c|c|c|c|c|c|}
\hline $\mathrm{G} 1-\mathrm{G} 2$ & $\begin{array}{l}25 \\
(36.8)\end{array}$ & 0.004 & $\begin{array}{l}19 \\
(32.2)\end{array}$ & $<0.001$ & $6(19.4)$ & 0.264 & $2(8.0)$ & $<0.001$ \\
\hline G3 & $\begin{array}{l}30 \\
(44.1)\end{array}$ & & $\begin{array}{l}27 \\
(45.8)\end{array}$ & & $\begin{array}{l}13 \\
(41.9)\end{array}$ & & $\begin{array}{l}10 \\
(40.0)\end{array}$ & \\
\hline
\end{tabular}

18

(58.1)
18

(72.0) 


\begin{tabular}{|c|c|c|c|c|c|c|c|c|}
\hline G4 & $\begin{array}{l}13 \\
(19.1)\end{array}$ & & $\begin{array}{l}13 \\
(22.0)\end{array}$ & & $\begin{array}{l}12 \\
(38.7)\end{array}$ & & $\begin{array}{l}13 \\
(52.0)\end{array}$ & \\
\hline \multicolumn{9}{|c|}{$\begin{array}{l}\text { Lymphovascular } \\
\text { invasion, } \mathrm{n}(\%)\end{array}$} \\
\hline No & $\begin{array}{l}57 \\
(83.8)\end{array}$ & 0.125 & $\begin{array}{l}50 \\
(84.7)\end{array}$ & 0.296 & $\begin{array}{l}22 \\
(71.0)\end{array}$ & 0.292 & $\begin{array}{l}17 \\
(68.0)\end{array}$ & 0.192 \\
\hline Yes & $\begin{array}{l}11 \\
(16.2)\end{array}$ & & $9(15.3)$ & & $9(29.0)$ & & $8(32.0)$ & \\
\hline
\end{tabular}

Sarcomatoid features, $n(\%)$

\begin{tabular}{lllllllll} 
No & 63 & 0.495 & $\begin{array}{l}53 \\
(89.8)\end{array}$ & 0.069 & $\begin{array}{l}27 \\
(87.1)\end{array}$ & 0.900 & $\begin{array}{l}19 \\
(76.0)\end{array}$ & 0.020 \\
\hline Yes & $(92.6)$ & & & & & \\
\hline
\end{tabular}

Tumor necrosis, $\mathrm{n}(\%)$

\begin{tabular}{|c|c|c|c|c|c|c|c|c|}
\hline No & $\begin{array}{l}48 \\
(70.6)\end{array}$ & 0.081 & $\begin{array}{l}40 \\
(67.8)\end{array}$ & 0.028 & $\begin{array}{l}16 \\
(51.6)\end{array}$ & 0.733 & $\begin{array}{l}10 \\
(40.0)\end{array}$ & 0.048 \\
\hline Yes & $\begin{array}{l}20 \\
(29.4)\end{array}$ & & $\begin{array}{l}19 \\
(32.2)\end{array}$ & & $\begin{array}{l}15 \\
(48.4)\end{array}$ & & $\begin{array}{l}15 \\
(60.0)\end{array}$ & \\
\hline
\end{tabular}

IMDC risk

classification

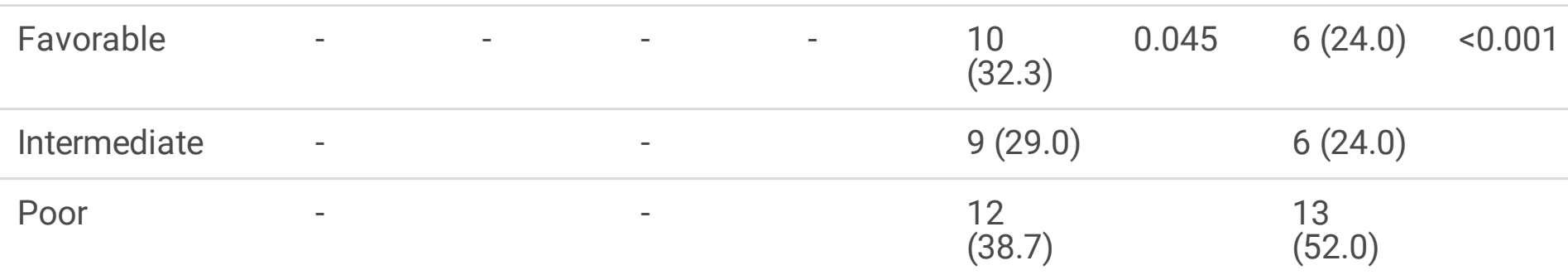

\section{Figures}


HE

a

b
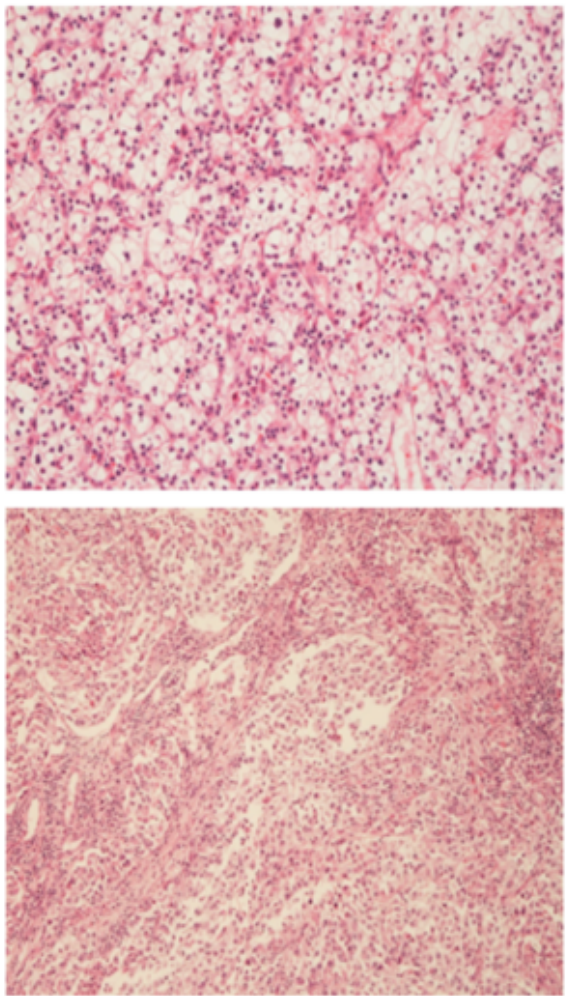

LAG-3
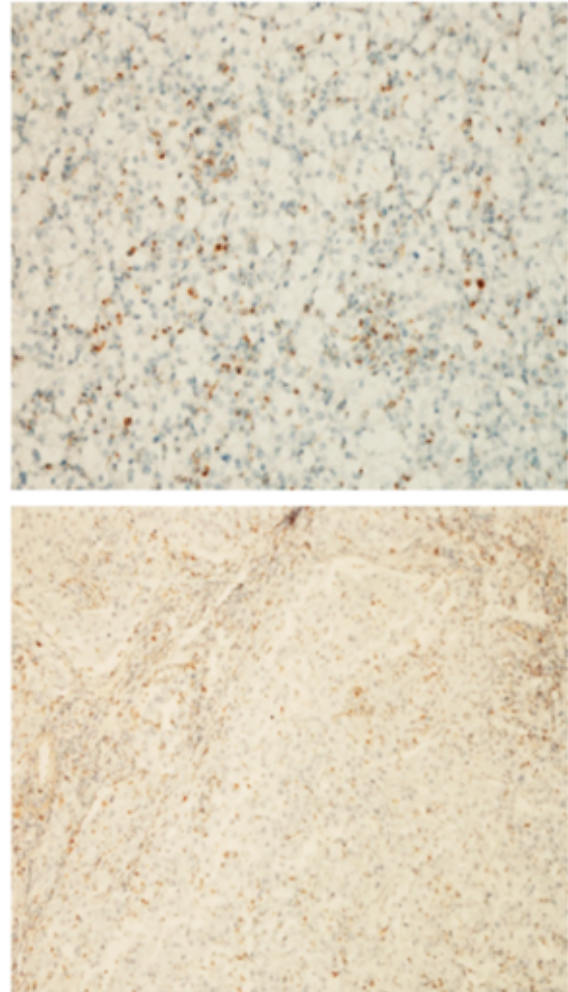

PD-L1
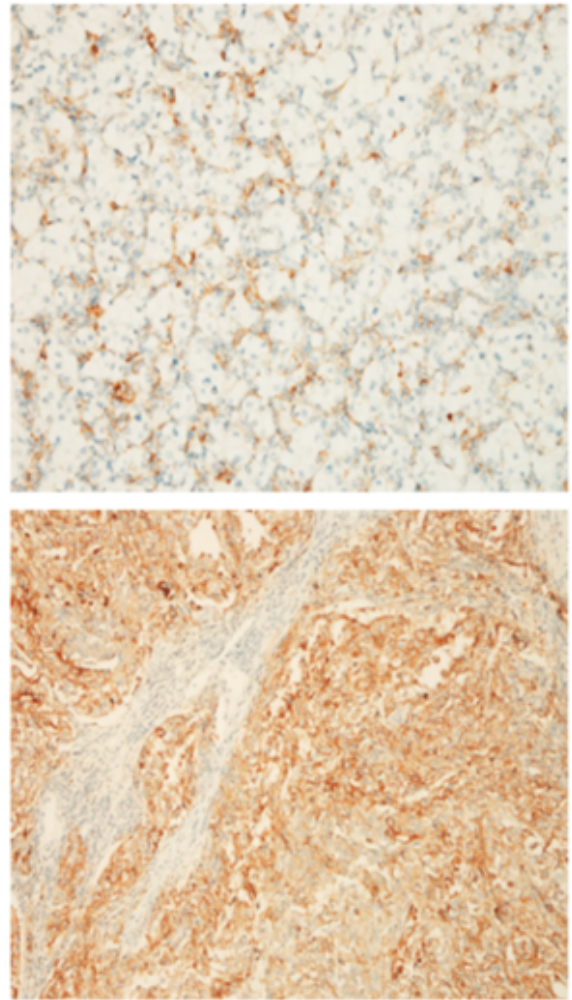

\section{Figure 1}

Expression of lymphocyte-activation gen 3 (LAG-3) by immunohistochemistry according to Fuhrman nuclear grade of clear cell renal cell carcinoma. Fuhrman grade 2 (a), grade 3 (b), grade 4 (c), sarcomatous differentiation (d). Original magnification, $x 200$ 


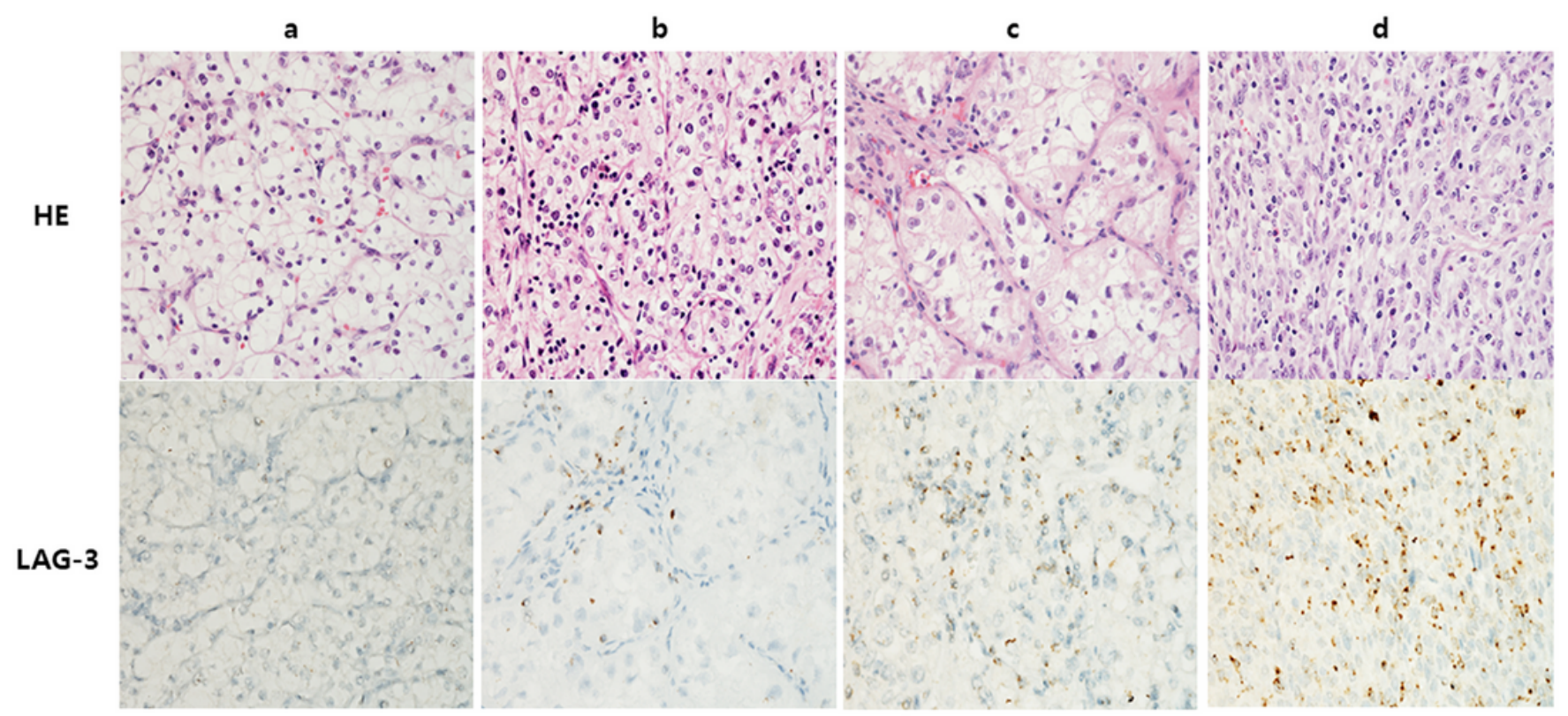

\section{Figure 2}

Expression of lymphocyte-activation gen 3 (LAG-3) and programmed cell death ligand-1 (PD-L1) by immunohistochemistry on serial section of same tissue. (a) LAG-3 and PD-L1 in immune cells (ICs) (b) LAG3 in ICs and PD-L1 in tumor cells (TCs)

\section{Figure 3}

Kaplan-Meier curves of cancer specific survival (CSS) in the whole cohort and metastatic renal cell carcinoma according to expression of lymphocyte-activation gen 3 (LAG-3) and programmed cell death ligand-1 (PD-L1). CSS in patients with LAG-3+ (a) and PD-L1+ (b) were significantly lower than with LAG-3and PD-L1- $(p=0.0016, p=0.0236)$. PD-L1+/LAG-3+ group was showed significantly lower CSS than PDL1-/LAG-3-, PD-L1-/LAG-3+ and PD-L1+/LAG-3- groups ( $p=0.0014, p=0.0022, p=0.0474)$ (c) in whole cohort. In metastatic RCC group, LAG-3+ patients were significantly lower than LAG-3- patients $(p=0.0369)$ (d) and PD-L1+ patients were showed lower CSS than PD-L1- $(p=0.0639)$ (e). PD-L1+/LAG-3+ group was showed significantly lower CSS than PD-L1-/LAG-3-, PD-L1-/LAG-3+ and PD-L1+/LAG-3- groups $(p=0.0389$, $p=0.0149, p=0.0401$ ) (f)

\section{Supplementary Files}

This is a list of supplementary files associated with this preprint. Click to download. 
- SupplementaryTable1.UnivariateandmultivariateCoxproportionalanalysisallpatients.docx

- SupplementaryTable2.UnivariateandmultivariateCoxproportionalanalysismRCCpatients.docx 